\title{
IDENTIDADE NEGRA EM NARRATIVAS INFANTIS: a memória como alicerce construtor da identidade negra dentro das identidades
}

\author{
Claudia Souza Santos ${ }^{1}$ \\ João Diogenes Ferreira dos Santos 2
}

\begin{abstract}
RESUMO
Apresentamos neste artigo o resultado de uma pesquisa de mestrado intitulada de "Memória e Educação: construções da identidade étnica-racial de estudantes negras do ensino fundamental de uma escola da rede pública municipal da cidade de Jequié-BA" que buscou identificar construções de identidades étnicoraciais através de concepções de raça e racismo presente em narrativas de estudantes negras. Para tanto, construimos uma discussão na perspectiva das relações étnico-raciais no que tange aos processos sociais, históricos e subjetivos das construções da identidade negra. A pesquisa se configura de cunho sociológico, tendo como base metodológica entrevistas semiestruturadas. Como referência trazemos as concepções de: Fanon, Gomes, Hall, Munanga, Schwarcz, Ariès, Corsaro, Pollak, Halbwachs, dentre outros. Os resultados obtidos por meio deste estudo sugerem que: a) as estudantes negras se percebem negras, conhecem os comportamentos de racismo, mas não compreendem porque este comportamento acontece; b) as estudantes negras querem ser aceitas como negras e buscam, para isso, assimilações de padrões de beleza negra já aceitos.
\end{abstract}

Palavras-chave: Identidade negra. Memória. Narrativas infantis.

\section{BLACK IDENTITY IN CHILDREN'S NARRATIVES: memory as a constructive}

\section{foundation of black identity within identities}

\begin{abstract}
In this article we present the results of a master's research entitled "Memory and Education: constructions of ethnic-racial identity of black elementary school students of a municipal public school in the city of Jequié-BA" which sought to identify constructions of ethnic-racial identities through conceptions of race and racism present in narratives of black students. To this end, we constructed a discussion from
\end{abstract}

\footnotetext{
${ }^{1}$ Estudante do Mestrado em Memória: Linguagem e Sociedade da Universidade Estadual do Sudoeste da Bahia (UESB). Vitória da Conquista, Bahia, Brasil. Orcid iD: http://orcid.org/00000001-9930-2700. E-mail: clodeslilla@gmail.com

${ }^{2}$ Doutor em Ciências Sociais. Professor titular da Universidade Estadual de Feira de Santana (UEFS). Docente do Programa de Pós-Graduação em Memória: Linguagem e Sociedade (PPGMLS) da Universidade Estadual do Sudoeste da Bahia (UESB). Vitória da Conquista, Bahia, Brasil. Orcid iD: https://orcid.org/0000-0001-5924-9773. E-mail: jdiogenes69@gmail.com
} 
the perspective of ethnic-racial relations regarding the social, historical and subjective processes of the constructions of black identity. The research is sociological in nature, with semi-structured interviews as the methodological basis. As a reference we bring the conceptions of: Fanon, Gomes, Hall, Munanga, Schwarcz, Ariès, Corsaro, Pollak, Halbwachs among others. The results obtained through this study suggest that: a) black students perceive themselves as black, know the racism behaviors, but do not understand why this behavior happens; b) black students want to be accepted as black and seek for this, assimilations of standards of black beauty already accepted.

Keywords: Black identity. Memory. Children's narratives.

\section{LA IDENTIDAD NEGRA EN LA NARRATIVA INFANTIL: la memoria como fundamento constructivo de la identidad negra dentro de las identidades}

\section{RESUMEN}

En este artículo presentamos los resultados de una investigación de maestría titulada "Memoria y Educación: construcciones de identidad étnico-racial de alumnos negros de una escuela pública municipal de la ciudad de Jequié-BA" que buscó identificar las construcciones de identidades étnico-raciales a través de las concepciones de raza y racismo presentes en las narrativas de los alumnos negros. Para ello, construimos una discusión desde la perspectiva de las relaciones étnicoraciales sobre los procesos sociales, históricos y subjetivos de las construcciones de la identidad negra. La investigación es de carácter sociológico, teniendo como base metodológica las entrevistas semiestructuradas. Como referencia traemos las concepciones de: Fanon, Gomes, Hall, Munanga, Schwarcz, Ariès, Corsaro, Pollak, Halbwachs entre otros. Los resultados obtenidos a través de este estudio sugieren que: a) los estudiantes negros se perciben a sí mismos como negros, conocen los comportamientos del racismo, pero no entienden por qué se produce este comportamiento; b) los estudiantes negros quieren ser aceptados como negros y buscan para ello, asimilaciones de los estándares de belleza negra ya aceptados.

Palabras clave: La identidad negra. La memoria. Los relatos de los niños.

\section{INTRODUÇÃO}

As identidades são construídas por meio dos processos de assimilação e reformulação subjetiva mediadas pelas relações socias que fazem parte do meio em que o indivíduo vive e atua. Diante disso, observamos o caminho teórico das discussões sobre a identidade negra que passa inicialmente por concepções que discutem a formação da identidade de forma geral. Através destas discussões observamos que o conceito de identidade é um dos mais complexos e elásticos discutidos na contemporaneidade. A complexidade encontra-se nas diversas ciências 
que a estudam a partir de suas bases teóricas que partem de conceitos biológicos, psicológicos, antropológicos e sociais. A elasticidade se dá em virtude do conceito passivo de modificação e modelagem, compreendendo valores éticos, reflexões morais e contextos culturais, nos quais o sujeito se define ou é definido. Por meio desses elementos, as muitas identidades já demarcadas em nossa cultura são readequadas e reinventadas cada vez que um sujeito legitima o seu ser. Neste contexto, a identidade negra é uma possível construção dentre estas identidades (MUNANGA, 2005).

No sistema escravista a diferença de cor e as características físicas da população africana foram usadas para a subjugação e dominação deste povo. A partir disso, o povo negro é visto como culturalmente inferior. Esta visão a respeito do grupo negro sedimentou o preconceito de cor que, no Brasil, atuou como mecanismo de segregação durante todo o período escravista, passando pelas concepções biológicas de raça no século XVIII que separaram a humanidade por raças, ainda presente na sociedade (SCHWARCZ, 2012).

Desta forma, é difícil olhar o presente sem considerar aspectos passados, já que o processo histórico é imprescindível para a visão crítica da atualidade.

A partir deste entendimento, desenvolvemos uma pesquisa a nível de mestrado intitulada de "Memória e Educação: construções da identidade étnico-racial de estudantes negras do ensino fundamental de uma escola da rede pública municipal da cidade de Jequié-BA".

Com o compromisso de trazer à tona os conceitos de identidade negra das estudantes informantes da pesquisa, usamos como recursos metodológico entrevistas semiestruturadas por entendermos que a característica de ouvir atentamente cada uma dessas estudantes a respeito de seus entendimentos sobre raça, racismo e suas declarações de pertença dá a esta pesquisa o seu caráter singular. Além disso, demonstra sua relevância para a discussão da formação da identidade negra em crianças na idade escolar que corresponde ao ensino fundamental, pois segundo 
Delgado e Muller (2005) existe uma necessidade de pesquisa com crianças já que, para estas autoras, o que existe são pesquisas sobre crianças - desse modo, a criança passa de mero observado para interlocutor atuante e ativo na pesquisa.

Assim sendo, o objetivo geral que norteou a pesquisa foi: identificar como estudantes negras do ensino fundamental de uma escola da rede pública municipal da cidade de Jequié-BA constroem suas identidades étnico-raciais. Sendo os objetivos específicos: analisar qual a percepção de racismo possui as estudantes negras desta escola; identificar quais os demarcadores culturais e étnico-raciais que influenciam no processo de construção da identidade étnico-racial das estudantes.

A partir da revisão bibliográfica decidimos previamente que a metodologia da pesquisa seria entrevistas semiestruturadas com estudantes autodeclaradas negras, matriculadas e frequentantes do ensino fundamental de uma escola da rede pública municipal da cidade de Jequié-BA. A escolha da escola se deu em decorrência dela estar situada na periferia da cidade e ter uma grande incidência de crianças negras e pardas matriculas, além de o acesso que a direção e o corpo docente deram para realização da pesquisa. Diante disto, perguntamos a algumas estudantes aleatoriamente nos corredores da escola - Qual a cor de sua pele? Diante das declarações de negras ou pardas, convidamos para uma entrevista. Assim, a pesquisa foi realizada no período de maio a dezembro de 2018 com 10 estudantes de 8 a 14 anos de idade.

Por questões de ética e anonimato das estudantes, escolhemos identificar as entrevistadas com os nomes dos orixás yabás (femininas) cultuadas no Candomblé no Brasil, que de acordo com Verger (1981), segue a tradição de culto aos orixás oriundos da África. A escolha dos nomes das yabás para representar as estudantes nos ocorreu por serem estas orixás yabás, mães, rainhas, guerreiras e deusas reverenciadas na cultura africana tanto no Brasil e na África como em outros continentes.

Assim sendo, apresentamos a organização deste artigo que está distribuído, além desta introdução, em outras três seções, que são: A 
memória e as identidades, que traz os conceitos da identidade sob a luz da memória e da subjetividade; A identidade negra dentro das identidades, que pontua a construção da identidade negra dentro dos processos identitários; Narrativas das yabás estudantes negras e, por fim, as considerações finais.

\section{A memória e as identidades}

Mesmo sendo a memória individual construída substancialmente no coletivo, Halbwachs (2006, p.41) afirma que não devemos "esquecermos que nossos sentimentos e nossos pensamentos mais pessoais têm sua origem em meios e circunstâncias sociais definidas" e ainda devemos nos lembrar do que buscamos nestas memórias, e não o que os outros buscam. Halbwachs (2006) acrecenta que, em geral, o indivíduo está encerrado em si mesmo, mas constrói para si um ambiente externo onde se comunica e se relaciona com o coletivo e traz para si novas impressões e assimilações.

Compreendemos que Pollak (1992), com base em Halbawchs, afirma que as identidades são construídas por meio dos processos de assimilação e reformulação subjetiva mediada pelas relações e atuações socias onde o indivíduo é envolvido. Nestes processos de assimilações subjetivas, os acontecimentos vividos pessoalmente e/ou "pelo grupo, ou pela coletividade à qual a pessoa se sente pertencer" (POLLAK, 1992, p.201), constitui elementos característicos da memória que formam o alicerce da subjetividade e consequentemente das identidades.

Para Hall (2006), a identidade, na visão sociológica, põe o sujeito em constante troca com o seu exterior:

A identidade, nessa concepção sociológica, preenche o espaço entre o "interior" e o "exterior" - entre o mundo pessoal e o mundo público. O fato de que projetamos a "nós próprios" nessas identidades culturais, ao mesmo tempo em que internalizamos seus significados e valores, tornando-os "a de nós", contribui para alinhar nossos sentimentos subjetivos com os lugares objetivos que ocupamos no mundo social e cultural. A identidade, então, costura (ou, para usar uma metáfora médica, "sutura") o 
sujeito à estrutura. Estabiliza tanto os sujeitos quanto os mundos culturais que eles habitam, tornando ambos reciprocamente mais unificados e predizíveis (HALL, 2006, p.11-12).

Podemos observar, num sentido amplo, que estes pensadores contextualizam a identidade como um desenvolvimento contínuo da subjetividade dada às relações e interações do sujeito em uma construção dinâmica que parte da consciência de si através das relações subjetivas, das comunicações, da linguagem e das experiências sociais vividas.

À vista disso, tendo a memória como base, vê-se que o processo de construção da identidade pode ser comparado ao processo civilizador da sociedade brasileira que, através de seus costumes, tempos e conflitos, segue por caminhos de construção histórica. Assim, entende-se que o processo de construção da identidade negra está relacionado com toda a história de vida dessas pessoas, ao longo de suas experiências sociais, culturais, econômicas, familiares e educacionais.

\section{A identidade negra dentro das identidades}

Munanga (2003) diz que a tomada de consciência da identidade negra não surge de uma percepção de diferença de cor de pele e das características físicas entres pessoas negras e brancas. $\bigcirc$ autor menciona que "Ela resulta de um longo processo histórico que começa com o descobrimento no século XV do continente africano e de seus habitantes pelos navegadores portugueses" (MUNANGA, 2003, p.37). O resultado desta descoberta foi a escravidão dos povos negros no Brasil e em outras partes do Ocidente.

A aculturação é uma consequência natural na relação entre culturas diferentes, mas também provoca uma perda das identidades originais, que infundidas, surge nova identidade, novas configurações. Deste modo, Munanga (2010) com base no processo diaspórico, norteia como devemos observar o histórico do/a negro/a brasileiro/a, pois ao contrário dos de seus compatriotas oriundos de outros continentes, que vieram para o Brasil 
voluntariamente, os africanos foram trazidos a força, sequestrados, nem sabiam para onde estavam sendo levados e por quais motivos.

Para entender a dificuldade do povo negro em construir e/ou reconstruir sua identidade étnica diante do processo de negação que se iniciou na Colônia com a diáspora forçada do povo negro, observamos a pergunta de Hall (2003):

Como podemos conceber ou imaginar a identidade, a diferença e o pertencimento, após a diáspora? Já que "a identidade cultural" carrega consigo tantos traços de unidade essencial, unicidade primordial, indivisibilidade e mesmice, como devemos "pensar" as identidades inscritas nas relações de poder, construídas pela diferença, e disjuntura? (HALL, 2003, p.28).

Fazendo uma analogia com a história do povo Judeu, Hall (2003) sublinha que a ideia constante de retorno a sua terra natal funciona como uma cura para as feridas, onde a fixação e cultuação de uma cultura anterior proporcionam uma ligação constante com o passado, com o lugar para onde se deseja voltar. É o que ele chama de "tradição", esses processos não acontecem de modo apenas subjetivo, mas de forma concreta, através da reprodução de costumes, como dança religião e comidas.

Porém, assumir a identidade negra não "significa necessariamente um retorno às tradições. É a negação do dogma da supremacia em relação à cultura do povo dominado" (MUNANGA, 2009, p.45). A negritude contempla um horizonte em que as diferenças não mais sejam mantidas, tendo a escravidão e as relações de poder como as únicas referências para a diferenciação entre sujeitos das mais distintas etnias.

Quando Munanga (2009) refere-se à negação do dogma hegemônico, isso representa assumir a identidade negra consciente de sua importância histórica, cultural e social, bem como sua contribuição no desenvolvimento local, pois é a partir da tomada de consciência dessas culturas de resistência que se constroem as identidades culturais enquanto 
processos e jamais como produtos acabados. Assumir-se negro/a é tão delicado e complexo quanto classificar a população brasileira, considerando os muitos matizes e a correlação político-social implicada nessa questão. O sujeito precisa se reconhecer na história, para então, perceber-se autor de sua história e assumir-se negro/a. Por isso é tão importante a formulação de políticas públicas que traga a história e a cultura do negro no Brasil para o centro das atenções nacionais, como menciona Munanga (2012):

Daí a necessidade e importância de ensinar a história da África e a história do negro no Brasil a partir de novas abordagens e posturas epistemológicas, rompendo com a visão depreciativa do negro, para que se possam oferecer subsídios para a construção de uma verdadeira identidade negra. (MUNANGA, 2012, p.10-11).

A temática negra não é um conteúdo estático como os das disciplinas de exatas, ela conta a história de uma civilização milenar, com toda uma trajetória. Na aplicação desta disciplina nas escolas brasileiras, podemos observar que esta atinge de forma direta a educação e a formação da identidade das crianças, especialmente das crinças negras. Uma vez que a construção da identidade negra é cercada pela interferência de outras identidades.

Gomes (2005) menciona a escola como sendo um dos espaços mais contundentes neste processo influenciador e esclarece:

Sendo entendida como um processo contínuo, construído pelos negros e negras nos vários espaços - institucionais ou não - nos quais circulam, podemos concluir que a identidade negra também é construída durante a trajetória escolar desses sujeitos e, nesse caso, a escola tem a responsabilidade social e educativa de compreendê-la na sua complexidade, respeitála, assim como às outras identidades construídas pelos sujeitos que atuam no processo educativo escolar, e lidar positivamente com a mesma (GOMES, 2005, p.44). 
A autora fala da importância do trabalho em sala de aula com a questão racial, pois representa uma forma de se construir entendimento sobre as diferenças raciais buscando afirmar e valorizar essas diferenças bem como a identificação e o combate a situações de racismo principalmente dentro dos espaços escolares, pois "nós, negros, somos educados desde a infância para nos anularmos a fim de sermos aceitos pelo 'outro'". Mas travestir-se nesse outro não é fácil e suas consequências são nefastas à constituição da identidade racial (GOMES, 1996, p.81).

Contudo, a temática negra ainda enconta barreiras para ser desenvolvida nas práticas escolares, pois de acordo com Santos e Marciel (2020), em uma pesquisa feita em escolas do ensino fundamental que buscou investigar as representações acerca da constituição da identidade negra em textos e livros didáticos de Língua Portuguesa, mostrou que apesar das escolhas dos livros serem feitas pelos professores, que em seus cotidianos são estes "determinados pelos condicionamentos de ordens diversas e livres para operar suas escolhas no momento de focalizar seus dizeres. Também é coagido pelos dados da situação de comunicação" (2020, p.10). Ou seja, a escolhas dos livros passam pela motivação dos professores, mesmo para além destas motivações ficou constatado "que em sua integralidade a cultura afro-brasileira não é abordada cotidianamente nos livros das escolas" (SANTOS e MARCIEL, 2020, p. 11).

Portanto, a discussão sobre as construções de identidade negra desenvolvida neste artigo, a partir de narrativas de estudantes negras, traz uma relevância à medida que tomamos conhecimento destas percepções identitárias através das narrativas das próprias estudantes. Que constrói sua identidade através não somente de suas percepções dos seus fenótipos físicos, mas também a partir do olhar do outro sobre si. Que é um dos fatores determinantes na construção desta identidade.

Sendo assim, Gomes (2002) ressalta a importância da pesquisa social com crianças negras nos seus processos escolares, tendo fenótipos como ponto de discussão: 
Poderemos, então, captar as impressões, representações e opiniões dos sujeitos negros sobre a escola, elegendo, com base nesses dados, temáticas que nem sempre são destacadas em nosso campo de atuação e que mereceriam um estudo mais profundo. A relação do negro com o corpo e o cabelo é uma dessas temáticas (GOMES, 2002, p .40)

Como caminho para isso, a autora acima sugere uma escuta atenta dessas crianças. Foi o que tentamos fazer nesta pesquisa, e o resultado dessa escuta é o que discutiremos a seguir.

\section{Narrativas das yabás estudantes negras}

Ao buscarmos responder o questionamento inicial; como estudantes negras do ensino fundamental de uma escola da rede pública municipal da cidade de Jequié-BA constroem suas identidades étnico-raciais? - que apresentamos neste artigo através das narrativas das yabás, levamos em consideração que os termos negra e preta já eram de conhecimento destas yabás. Assim, contamos que das dez yabás entrevistadas na pesquisa, nove se autodeclararam de cor negra/parda e uma disse ser indígena.

Conforme Gomes (2002, p.49) "a experiência corporal é sempre modificada pela cultura, segundo padrões culturalmente estabelecidos e relacionados à busca de afirmação de uma identidade grupal específica". Ora, diante disso, ter a pele escura, aliada às transformações artificiais a que - corpo possa ser submetido, podem fazê-lo transitar por diversas identidades, e não necessariamente a negra (GOMES, 2002).

Desta forma, apenas com base nas respostas de autodeclaração de cor/raça das yabás, não é possível afirmar que elas possuem identidade negra construída.

Ao perguntarmos sobre gosto pelos seus cabelos, as yabás entrevistadas afirmam gostar do próprio cabelo, porém, quando indagadas sobre querer mudar algo no próprio corpo nos deparamos com declarações contraditórias como a da yabá Yewá (14 anos) que diz:

Não gosto [do meu cabelo], queria que fosse cacheado [...] queria mudar meu rosto, o cabelo, ter a pele mais escura, ter 
um rosto diferente, os meninos me acham feia, me chama de negra preta, só porque o cabelo, né, tipo assim, não é igual ao da gente, xinga de cabelo duro, mas eu não concordo (YEWÁ, 14 ANOS).

Observamos, por meio deste trecho da narrativa que Yewá tem dúvida se é feia ou bonita. A insegurança com a própria estética é efeito do racismo que, como código ideológico, estabelece os atributos físicos biológicos como importantes qualidades sociais, que impõem ao/a negro/a uma série de conotações negativas que o/a afetam social e subjetivamente (GOMES, 2002).

Sobre a estética do cabelo, outra yabá afirma: "queria ter o cabelo black, bem grande, porque ele [o cabelo] é meio liso" (OTIN, 13 ANOS). Notamos, aqui, que se trata do cabelo liso que não possui movimento, sendo então um cabelo liso "esticado", que continua estático (duro), portanto, não é considerado um cabelo "bom".

Continuam as narrativas da yabás sobre os cabelos: "Queria que fosse um pouquinho mais macio" (OBÀ, 12 ANOS). Ainda prossegue, "Gosto um pouco do meu cabelo, tem gente que acha ele feio, mas eu gosto, queria que fosse grande como o da minha mãe, porque acho mais ou menos "ruim", a minha mãe fala que cabelo "ruim" não cresce" (OXUM A, 9 ANOS). Bem como "Queria que fosse liso e grande" (IEMANJÁ A, 9 ANOS). Nanã diz que "Eles me chamam de cabelo duro, de cabelo de serrote" (NANÃ, 10 ANOS). Já lemanjá fala que "Queria ter meu cabelo natural de volta, porque usei alisamento, mas não ficou bom, às vezes, ele fica um pouco embaraçado para poder pentear, aí eu mudaria um pouco o cabelo, queria que fosse assim, cacheado" (IEMANJÁ B, 10 ANOS).

Constatamos assim, que o cabelo crespo considerado "duro", "ruim", presente nas falas de algumas yabás caracteriza-se como o cabelo que não possui movimento, diferentemente daquele considerado "bom". Para Gomes (2008):

Ver o cabelo do negro como "ruim" e do branco como "bom" expressa um conflito. Por isso, mudar o cabelo pode significar a 
tentativa do negro de sair do lugar da inferioridade ou a introjeção deste. Pode ainda representar um sentimento de autonomia, expresso nas formas ousadas e criativas de usar o cabelo (GOMES, 2008, p.21).

Independentemente de onde venha a crítica (percepção própria, da família ou de colegas) sobre o cabelo crespo, ela já está "naturalizada" na sociedade, pois como afirma Gomes (2008, p.230) "o corpo é uma linguagem, e a cultura escolheu algumas de suas partes como principais veículos de comunicação. O cabelo é uma delas". É certo que os cabelos, para a pessoa que já possui o fenótipo da cor negra acentuada, carrega uma preocupação, especialmente por causa das construções sociais de dicotomia "bom" e "ruim" para a textura do cabelo, sendo "bom" para cabelos lisos ou levemente encaracolados, longos e com muito balanço e "ruim" para cabelos crespos, estáticos, curtos ou não. Gomes (2002) trata das experiências da criança negra com o cabelo e ressalta:

As experiências do negro em relação ao cabelo começam muito cedo. Mas engana-se quem pensa que tal processo inicia-se com o uso de produtos químicos ou com o alisamento do cabelo com pente ou ferro quente. As meninas negras, durante a infância, são submetidas a verdadeiros rituais de manipulação do cabelo, realizados pela mãe, tia, irmã mais velha ou pelo adulto mais próximo. As tranças são as primeiras técnicas utilizadas. Porém, nem sempre elas são eleitas pela então criança negra (GOMES, 2002, p.43).

Quisemos saber das yabás entrevistadas se elas possuíam um referencial de beleza. Se estas tinham uma pessoa que elas consideram bonita; para tanto, pedimos a descrição física dessas pessoas. E assim disseram as yabás. "Minha prima ela é bonita, branca tem cabelo liso, longo e preto" (YEWÁ, 14 ANOS). "Eu mesma" (OTIN, 13 ANOS). "Minha colega aqui da escola, ela é bonita, é branca, tem cabelo liso, grande e preto" (OYÁ A, 13 ANOS). "Minha colega aqui da escola, ela é bonita é branca tem cabelo liso, grande, preto e os olhos verdes" (OBÁ, 12 ANOS). "Minha mãe, ela é da mesma cor que eu, só que tem cabelo grande e liso, ele é preto" (OXUM A, 9 ANOS). "Minha colega, ela é bonita, parda tem os cabelos cacheados, 
curtos e pretos" (YEMANJÁ A, 9 ANOS). "Ivete Sangalo" (NANÃ, 10 ANOS). "Minha colega bonita. Ela é branca e tem cabelos cacheados castanhos" (YEMANJÁ B, 10 ANOS). "Minha tia, ela é bonita é parda e também tem cabelos black" (OXUM A, 11 ANOS). "Minha mãe, ela é bonita, branca de cabelos cacheados e pretos" (OYÁ B, 11 ANOS).

Através dos trechos acima, podemos perceber que os fenótipos brancos (pele branca, cabelo liso) estão em vantagem na percepção destas yabás em relação aos fenótipos negros (pele preta, cabelo crespo) ou seja, para o corpo negro continua sendo imposto a referência do corpo branco como forma de aceitação em um processo de rememoração, de retorno ao que foi construído ao longo do tempo sobre o padrão de beleza.

A beleza, de um modo geral, está diretamente ligada ao cabelo e à pele; aqui, em especial, aos padrões impostos ao corpo negro, que como diz Gomes (2008):

Ao falarmos sobre corpo e cabelo, inevitavelmente, nos aproximamos da discussão sobre identidade negra. Essa identidade é vista, no contexto desta pesquisa, como um processo que não se dá apenas a começar do olhar de dentro, do próprio negro sobre si mesmo e seu corpo, mas também na relação com o olhar do outro, do que está fora (GOMES, 2008, p. 2).

A partir da visão de estética não somente do olhar de si, mas também e, principalmente, do olhar do outro, buscamos conhecer qual perspectiva as estudantes yabás têm de sua própria beleza. A yabá Yewá (14 anos) relata se achar bonita, mas não acredita que outras pessoas também the achem bonita e ela não sabe dizer o porquê. A yabá Oyá A (13 anos) se acha bonita, mas não sabe se outras pessoas Ihe acham bonita, porém diz: "falam que sou bonita". Ao ser perguntada se estas pessoas são suas conhecidas, ela informa: "Tem umas que é tem outras que não". A yabá Obá (12 anos) se acha bonita "de vez em quando". Sobre as outras pessoas que a acham bonita, destaca: "minhas colegas, minhas tias, meus primos me acham bonita. Tudo de convivência comigo". A yabá Oxum A (9 anos) se 
considera bonita e informa que há outras pessoas que compartilham dessa opinião: "Minhas colegas, pessoas da minha família, todo mundo me acha bonita". Também a yabá Yemanjá A ( 9 anos) se acha bonita e informa que outras pessoas também acham. A yabá Oyá B (11 anos) se considera bonita, mas acredita que só sua família concorde com isso, outras pessoas não.

A yabá Otin (13 anos) diz que se acha bonita, mas acha que só "algumas pessoas" a acham bonita. Questionada sobre o porquê de pensar assim, ela diz: "É por causa da cor". Nesta conclusão, reformulamos a pergunta: você acha que as pessoas não the acham bonita por causa da sua cor? E ela responde: "ram ram" (balançando a cabeça em afirmação com expressão de choro, olhos baixos, alisando o antebraço esquerdo com a mão direita).

A yabá Yemanjá B (10 anos) diz se achar mais ou menos bonita. Questionada sobre o "mais ou menos", ela disse: "Assim, algumas pessoas falam que a minha aparência, a minha cor é meio usada, meio feia". Sobre quem são essas pessoas, ela diz: "São minhas amigas mesmo". Sobre o que ela acha disso ela diz: "Fico meio chateada". Em geral, outras pessoas the acham bonita? Ela responde: "Sim, meu pai, minha mãe, meus tios, minha avó, minhas primas".

A yabá Oxum B (11 anos) por sua vez, revela que se acha bonita, mas diz que outras pessoas não acham. Sobre quem são essas pessoas, ela ressalta: "São uns amigos anteriormente lá do meu outro colégio e uns que eu conheço que são da rua da minha vó, e muitos amigos da minha igreja. E meu irmão mais velho ele sempre me crítica e também fala que eu sou feia, fica me xingando isso tudo".

A yabá Nanã (10 anos) se considera bonita, mas sobre outras pessoas Ihe acharem bonita, assim diz: "Acham, só minha família e meus parentes, mas as pessoas de lá de fora não acham não". Questionada se sabe porque as outras pessoas não the acham bonita, ela diz que sabe, então perguntamos por que e ela diz que é porque as pessoas tem nojo, então perguntamos por qual motivo ela acha que as pessoas tem nojo e ela disse: "Porque tem gente morena, preta que quando as pessoas passam assim 
num lugar, um branco passa, aí a gente vai sentar num lugar, por exemplo um preto tá sentado na cadeira aí um branco vai não quer sentar mais, fica com nojo da pessoa".

A autoafirmação do ser no mundo se dá nas percepções das diferenças e semelhanças entre um indivíduo e outro. Essa relação de assimilação e subjetivação, de acordo com Corsaro (2011), é um processo que se inicia desde a infância, sendo que, nesse mesmo período geracional, já produz resultados próprios e distintos. No entanto, Fanon (2008, p.129) nos diz que "uma criança negra, normal, tendo crescido no seio de uma família normal, ficará anormal ao menor contato com o mundo branco. Como talvez esta proposição não seja compreendida de imediato, avançaremos retrocedendo".

Dessa forma, as crianças negras iniciam suas trajetórias de vida social organizando implicitamente um jogo simbólico, onde o desenvolvimento só se dá em decorrência de luta, de desafio ou de enfrentamento das dificuldades que sempre aparecem e continuarão aparecendo ao longo da vida (MUNANGA, 2005).

No caso das estudantes yabás, elas demonstram através de suas falas que as suas experiências coletivas produzem sentidos de que elas não são aceitas, pois essas percepções estão atreladas a suas memórias. Com base em Halbwachs (2006), essas memórias podem ser de experiências vividas, pessoais ou de outros, não apenas a percepção do passado, mas é a necessidade do presente que busca no passado essas memórias. Ou seja, são memórias não necessariamente vividas pelo indivíduo que recorda, porém, pela necessidade do presente, ele reformula essas imagens do passado não por acaso, mas em decorrência das situações atuais.

O racismo, segundo Munanga (2008), é uma construção conceitual e terminológica oriunda do preconceito de cor do século XVII, passando pelo preconceito racial do século $\mathrm{XX}$, sendo formulado a partir das pautas políticas e sociais. Também deve ser entendido como sendo um conjunto de atitudes e conceitos produzidos e reproduzidos pela sociedade com claros 
objetivos de dominação e segregação, acompanhados de um discurso que legitima esse sistema.

A partir desta compreensão, ouvimos os relatos das yabás entrevistadas sobre algumas experiências vividas ou presenciadas de maustratos em decorrência da cor da pele e/ou por causa do cabelo, que elas classificam como sendo racistas.

Yewá (14 anos) informa que ela mesma já foi maltratada, e conta: "Aqui na escola tem um bocado de meninos que ficam xingando a gente. Me chama de nega preta, só porque o cabelo né, tipo assim, não é igual ao da gente, xinga de cabelo duro". Ela também afirma que já foi maltratada na escola outras vezes. Perguntada se ela sabe por que as pessoas negras são maltratadas, disse: "Assim mais ou menos, só por causa que tem um tom da pele diferente porque é meio morena e as pessoas brancas não sei porque fica... fica assim, tendo esses maus-tratos com as pessoas negras" (YEWÁ, 14 ANOS).

A narrativa dessa yabá demonstra sua compreensão de que a cor da pele das pessoas negras é um fator determinante para serem maltratadas pelas pessoas bancas. Esta percepção parte não somente da observação desta yabá sobre os comportamentos dos outros com os outros, mas também do comportamento classificatório dos outros com ela mesma.

Esta outra yabá diz que já viu pessoas sendo maltratadas por causa da cor da pele e do cabelo: "A minha amiga J. os povos a chamavam de chucky. Porque os povos têm preconceito com ela. Pra mim é preconceito". Apesar de afirmar que nunca foi maltratada por causa da cor de sua pele ou de seu cabelo, a yabá Oyá A (13 anos) demonstra em sua narrativa, reconhecer uma situação de racismo e quais são os motivos que leva uma pessoa a cometer tal ato.

Já a yabá Otin ( 13 anos) afirma que ela mesma já foi maltratada: "É porque eu vinha para a escola que nem uma doidinha, aí os meninos ficavam me xingando. Eu não penteava o cabelo, vinha com a mesma roupa parecendo uma doida". Quando perguntamos a essa Yabá se o ato de pentear o cabelo fazia diferença, ela afirma que sim. 
Um olhar sobre si mesmo e seu corpo a partir de uma mediação tensa e conflituosa realizada entre a expressão da estética do corpo negro com o olhar do que está de fora. Gomes (2008, p.20) coloca que "nessa mediação, um ícone identitário se sobressai: o cabelo crespo. O cabelo e o corpo são pensados pela cultura. Por isso não podem ser considerados simplesmente como dados biológicos", pois estes são fenótipos usados para reforçar a "construção social, cultural, política e ideológica de uma expressão criada no seio da comunidade negra: a beleza negra".

Porém, na declaração "Eu não penteava o cabelo", da yabá Otin (13 anos) observamos que o cabelo crespo pensado pela cultura deve se encaixar em padrões normativos de disciplina, pentear o cabelo neste contexto significa mais do que se arrumar, significa domar, disciplinar "o cabelo rebelde". Estas declarações nos fazem refletir sobre as situações de racismo que os negros sofrem em decorrência da textura de seu cabelo. $E$ como a identidade negra é entendida no contexto destas relações mesmo já sendo "o cabelo crespo e o corpo negro considerados expressões e suportes simbólicos da identidade negra no Brasil" (GOMES, 2008, p.20).

Um pouco diferente das demais, a yabá Obá (12 anos) diz que nunca viu ninguém ser maltrato por ser negro, mas destaca:

Muita gente sei lá querendo ser maior do que as pessoas negras. [...] As pessoas brancas se acham superior a gente por que o cabelo é mais sempre liso, a cor é mais clara do que a nossa de vez em quando tem olhos azuis, nós sempre temos olhos castanhos, castanhos mais escuros (OBÁ, 12 anos).

Em sua narrativa, a yabá Obá ( 12 anos) apesar de afirmar nunca ter sofrido situações de racismo, demonstra conhecimento das situações que o define bem quando fala dos negros na terceira pessoa, mas constantemente se coloca na cena nas situações de vítima. Desta forma, fica evidente sua compreensão de que as situações de racismo vividas por outras pessoas negras se referem a ela também.

Contradições na fala acontecem, pois esta yabá (OXUM A, 9 anos) informa que nunca foi maltratada por causa do cabelo ou da pele, afirma 
também não conhecer ninguém que tenha sofrido, porém, quando questionada se já viu alguma situação na escola, ela diz: "Tava brincando de os meninos pegar as meninas, aí ele era mais escurinho e a menina era branca aí a menina não quis pegar ele porque ele era feio e era negro". Mais uma vez questionada sobre ter sofrido alguma situação como esta, ela confirma: "Primeiro foi minha amiga, ela é daqui da escola também só que ela é branca. Ela não gosta de brincar muito comigo, ela gosta de brincar mais com as outras é isso. Ah é triste né! Por causa que ela é minha melhor amiga" (OXUM A, 9 anos).

Já a yabá Nanã (10 anos) confessa que sofre maus-tratos na escola e identifica o motivo: "Os meninos daqui mesmo da minha sala, eles me chamam de cabelo duro, de cabelo de serrote".

Mais uma vez, o cabelo aparece nas narrativas como fator de atitudes racistas. O cabelo crespo que em outras épocas era considerado ruim/feio em relação ao cabelo liso/bonito adquire na contemporaneidade através das reconfigurações da história e ressignificação da memória status de cabelo bonito e, portanto, aceito e desejado (GOMES, 2008). Mesmo assim, observamos através da narrativa da yabá Nanã (10 anos) que o cabelo crespo ainda sofre descriminação.

Esta yabá diz que já presenciou uma pessoa ser maltratada por causa do cabelo na escola mesmo. Questionada, então, sobre se ela mesma já sofreu maus-tratos por causa do cabelo ou da cor da pele, afirmou:

Sim, por causa do meu cabelo também. Eu não gosto de tocar nesta história, mas como estamos aqui eu vou falar. É assim, como o caso de C (colega da escola). que a gente estava brincando de salão de beleza, quando foi no outro dia começou a brincar no meu (cabelo). Aí arrumaram, fizeram uma trança lá, aí vieram os meninos a perturbar de novo... tipo C., aí começou falar que o meu cabelo era de bombril, assim... falando coisas que não deve, ultrapassou do limite (YEMANJÁ $B, 10$ ANOS).

Pensamos então que o risco de violência física, verbal e simbólica (BOURDIEU, 2002, p.7-8) que, porventura, possa ocorrer a essas yabás, por 
causa da cor de sua pele e/ou da textura de seu cabelo, possa acompanhá-las por toda a sua vida adulta, mesmo que novos conceitos sejam construídos para a substituição dos atuais.

A yabá Oxum B (1 1 anos), por sua vez, lembra que já viu pessoas sendo maltratadas por causa da cor da pele e narra a história de um homem que entrou no mercado para comprar e a dona achou que ele iria roubar, só porque ele era preto, ainda que no mesmo momento outro homem branco entrou e roubou coisas na prateleira. Para ela, esse comportamento é injusto. Sobre ela mesma ter sido maltratada, ela afirma que nunca, mas diz:

É que os meus colegas os meninos, as meninas não, os meninos eles gostam de humilhar a gente, com as brincadeiras meio de mau gosto. Pra eles são brincadeiras, que eles podem fazer, só que a gente é a vítima desse caso, eles ficam falando do nosso cabelo, do jeito de andar, da roupa que a gente usa, chamando a gente... e tem um menino aí da minha sala que ele gosta mesmo de criticar as minhas amigas e eu. $E$, um dia tinha um vídeo no celular, ele pegou esse vídeo e eram macacos no vídeo, ele falou que a gente eram aqueles macacos e ele gosta de chamar a gente de feia e várias coisas que ele fala do nosso cabelo e muitas coisas aí (OXUM $B, 11$ anos).

Oxum B (11 anos) menciona que prefere pensar que o que seus colegas fazem é um tipo de brincadeira, acredita que alguém tão próximo não pode the querer maltratar. Desta forma, podemos supor através da narrativa da yabá Oxum B (11 anos) que ela busca compreender o mundo a partir do olhar dela sobre outros, ou seja, prefere pensar que todos a vêem como ela se vê e como ela vê os outros, sob a perspectiva do bem-querer.

A yabá Oyá B (11 anos) diz que já viu pessoas sendo maltratadas por causa da cor da pele e ou do cabelo, e relata: "na televisão, e pessoalmente, comigo, com ela" neste momento ela aponta para si e para uma menina que se encontra na porta da sala e continua: "os meninos lá de baixo que eu não gosto ficam me chamando de nega preta". Sobre o que ela acha disso diz: "normal, eu sou preta mesmo. Acho normal, eu já estou acostumada com isso. Eu nem ligo. Fico triste, mas também eu xingo". Ao 
comentar porque as pessoas negras são maltratadas, argumenta o seguinte: "Porquê ô, tem gente que tem nojo de negro, só porque nós somos dessa cor e os povos brancos lá tem a cor mais bonita, é só isso". Diante desta resposta perguntamos se ela acha a cor branca mais bonita do que a cor negra e ela firma: "eu não, são os brancos que acham isso, são os brancos cometem racismo quando xingam a pessoa de nega preta, e xingam a pessoa de macaco, diz que é urubu".

Gomes (2003) ressalta as estratégias racistas usadas pela sociedade para segregar o negro e a negra:

Uma sociedade racista usa de várias estratégias para discriminar o/a negro/a. Alguns aspectos corporais, no contexto do racismo, são tomados pela cultura e recebem um tratamento discriminatório. São estratégias para retirar do/a negro/a o status de humanidade. Talvez seja esta uma das piores maneiras de o racismo se perpetuar. Ele transforma as diferenças inscritas no corpo em marcas de inferioridade. Nesse processo são estabelecidos padrões de superioridade/inferioridade, beleza/feiúra (GOMES, 2003, p.80).

A memória imbricada nas narrativas das yabás remonta às crônicas do cotidiano, que se constituem em um espaço vivido e imaginado, trazendo em suas ações temporais a compreensão de como a memória cultural entrelaçada a diferentes grupos sociais, coexiste como mediadora das construções das identidades destas estudantes yabás negras.

Deste modo, podemos concluir através das narrativas das yabás, estudantes colaboradoras da pesquisa, que elas se reconhecem como negras. E também conhecem situações racistas e sabem diferenciá-las de situações que não são. Estas yabás estudantes também sabem porque existem tais situações além de conhecerem de quais pessoas (grupo) advém o racismo e para quais pessoas (grupo) é direcionado.

Neste caso, suas narrativas tornam-se terrenos fecundos para se pensar como a memória, tecida em uma realidade entremeada pelo racismo, se constitui através do tempo e em determinado espaço. As diversas interpretações que se podem ter demonstram a incorporação de memórias 
marginalizadas e, por vezes, silenciadas, em um embate pela afirmação (POLLAK, 1992).

\section{CONSIDERAÇÕES FINAIS}

Neste artigo, buscamos mais do que apresentar o debate teórico de uma pesquisa acerca da construção da identidade negra, trazemos também, as narrativas analisadas de jovens estudantes negras em início do processo de construção de suas identidades.

Neste espaço escolar onde ocorreu a investigação, as informantes da pesquisa vivem situações de racismo semelhantes a situações que elas vivem em outros espaços sociais. Isto nos leva a refletir que mesmo com a implementação da Lei 10.639/03, que estabeleceu as diretrizes e bases da educação nacional para incluir no currículo oficial da rede de ensino a obrigatoriedade da temática "História e Cultura Afro-Brasileira e África", são visíveis algumas dificuldades de crianças negras no ambiente escolar, de se sentirem acolhidas e pertencentes, pois para que isso ocorra, essas crianças precisam estar resguardadas em uma consciência de grupo que seja valorizada e aceita, onde elas se sintam pertencentes e protegidas, para que elas possam assumir em seu ambiente social/escolar uma postura de autoconfiança frente a todas as injúrias atribuídas às características físicas de seu grupo étnico (RAMOS, 2015).

Desta forma, observamos a importância da educação neste contexto. Pois, pensar a educação é pensar como ela poderá, através de suas interligações, promover a emancipação ou a subserviência dos sujeitos envolvidos nesses processos.

Segundo a Lei No 9.394/96, que estabelece as diretrizes e bases da educação nacional sobre a finalidade da educação dentre outras pautas, conforme o Art. $2^{\circ}$, a educação deve ser [...]"inspirada nos princípios de liberdade e nos ideais de solidariedade humana, tem por finalidade o pleno desenvolvimento do educando", portanto, o verdadeiro objetivo da educação é promover o desenvolvimento das capacidades individuais e 
sociais, de cultura, de identidade e de valores a partir das relações com o outro, com o meio e consigo mesmo.

Assim sendo, conclui-se, através desta discussão, que a construção da identidade negra de cada yabá entrevistada passa por um percurso de autoafirmação construída na experiência coletiva destas yabás onde esta identidade é atravessada tanto por outras identidades quanto por outros sujeitos. Neste contexto, assimilam e constroem suas subjetividades relacionando com modelos apresentados e aceitos.

Ora, para essas estudantes como para outras crianças negras, construir sua identidade negra representa, então, um complexo jogo de encaixe. Vidas que se confrontam com o "racismo cordial", encoberto e sutil. Vidas que tentam driblar o incômodo e o sofrimento que a discriminação racial impõe por meio de comportamentos e falas, uma vez que, ao mesmo tempo em que desejam ser aceitas como são, também querem estar em conformidade com o modelo de negro/a apresentado. Por certo, estas estudantes negras entendem que são diferentes tanto entre si, como entre elas e as outras crianças brancas.

Elas também demonstram, em suas narrativas, que não desejam ser brancas, elas desejam serem aceitas como são, mesmo que esse ideal de aceitação as leve a pensar que dentro do grupo negro ao qual pertencem existe um modelo de negra/o a ser seguido.

No jogo da memória social, as yabás, estudantes negras colaboradoras desta pesquisa como atrizes sociais do grupo negro, que antes de se autodefinirem pretas ou pardas, já são definidas, regulamentadas e segregadas pelo grupo branco através da memória social do racismo, revelam então, suas memórias e assimilações que se constituem na memória subterrânea do grupo negro, ou seja, a memória dos que de acordo Pollak (1992, p.7). No entanto, "Iutam pelo reconhecimento de uma situação valorizadora das vítimas" da escravidão e da segregação, "mas hoje, essa memória canalizada e esterilizada se revolta e se afirma" contra a memória oficial praticada, assim, a memória subterrânea dos negros e de seus ancestrais "toma a dianteira e se erige então contra 
aqueles que tentaram forjar um mito, a fim de eliminar o estigma da vergonha" (POLLAK, 1992, p.7).

Neste jogo da memória racial, a posição do negro frente ao racimo é o que Fanon (2008) compreende como algo que:

[...] me atinge em plena carne, eu me emociono, esta contestação aterrorizante me debilita, negam-me a possibilidade de ser homem. Não posso deixar de ser solidário com o destino reservado a meu irmão. (FANON, 2008, p.87).

Ou seja, as lutas do povo negro fazem surgir as identidades negras em oposição às identidades brancas secularmente construídas como projeto de identidade ideal. O efeito disso é a autoidentificação do negro como tal, conforme podemos perceber nas falas das estudantes colaboradoras desta pesquisa, que, mesmo de forma ainda insegura, sabem o que pensam e dizem sobre elas, sabem o seu lugar de pertença e demostram ter conhecimento dos seus conceitos básicos.

\section{REFERÊNCIAS}

BOURDIEU, P. A dominação masculina. Tradução Maria Helena Kühner. Rio de Janeiro, $2^{a}$ ed. Bertrand Brasil, 2002.

BRASIL. Lei n 10.639, de 9 de janeiro de 2003. Altera a Lei n. 9.394, de 20 de dezembro de 1996. Diário Oficial da União. Brasília, 10 jan. 2003. Disponível em:http://www.planalto.gov.br/ccivil_03/leis/2003/l10.639.htm\#: :text=L10639 \&text=LEI\%2ONo\%2010.639\%2C\%20DE\%209\%20DE\%20JANEIRO\%20DE\%202003. \&text=Altera\%20a\%20Lei\%20no,\%22\%2C\%20e\%20d\%C3\%A1\%20outras\%20provi d\%C3\%AAncias. Acesso em: 08 de mai. 2016.

BRASIL. Lei n 9.394, de 20 de dezembro de 1996. Diário Oficial da União. Brasília, 23 dez.1996. Disponível em:http://www.planalto.gov.br/ccivil_03/leis/19394.htm. Acesso em: 08 de mai. 2016.

CORSARO, W. Sociologia da infância. Tradução de Lia Gabriele Regius Reis, Porto Alegre, Artmed, 2011.

DELGADO, A. C. C; MULLER, F. Em busca de metodologias investigativas com as crianças e suas culturas. Cadernos de Pesquisa, v. 35, n. 125, maio/ago. 2005 pp. 161-179. Diponivel em: 
http://publicacoes.fcc.org.br/ojs/index.php/cp/article/view/440/445. Acesso em: 12 de jul. 2019.

FANON, F. Pele negra, máscaras brancas. Tradução de Renato da Silveira. Salvador, EDUFBA, 2008.

GOMES, N. L. Educação, Raça e Gênero: relações imersas na alteridade. Cadernos Pagu (6-7), Campinas-SP, Núcleo de Estudos de GêneroPagu/Unicamp, 1996, pp. 67-82. Disponível em:

https://periodicos.sbu.unicamp.br/ojs/index.php/cadpagu/article/view/1862/ 1983. Acesso em: 19 de dez. 2019.

GOMES, N. L. Trajetórias escolares, corpo negro e cabelo crespo: reprodução de estereótipos ou ressignificação cultural? Revista Brasileira de Educação. $n^{\circ}$ 21. 2002. DOI: https://doi.org/10.1590/S1413-24782002000300004. Disponível em: https://www.scielo.br/scielo.php? script=sci_arttext\&pid=S141324782002000300004\&lng=pt\&nrm=iso. Acesso em: 08 de mai. 2016.

GOMES, N. L. Cultura negra e educação. Revista Brasileira de Educação. 2003, n 23, pp. 75-85. DOl: https://doi.org/10.1590/S1413-24782003000200006. Disponível em: https://www.scielo.br/scielo.php?script=sci_arttext\&pid=\$1413$24782003000200006 \&$ lng=pt\&nrm=iso. Acesso em: 25 abr. 2017.

GOMES, N. L. Sem perder a raiz: corpo e cabelo como símbolos da identidade negra. Belo Horizonte, $2^{\mathrm{a}}$ ed. editora Autentica, 2008.

GOMES, N. L. Alguns termos e conceitos presentes no debate sobre relações raciais no Brasil: Uma breve discussão. In: BRASIL. Educação Anti-racista: caminhos abertos pela Lei federal n ${ }^{\circ}$ 10.639/03. Brasília, MEC, 2005. pp. 39 62.

HALBWACHS, M. A memória coletiva. Tradução de Beatriz Sidou. São Paulo, Centauro, 2006.

HALL, S. Da Diáspora: identidade e mediações culturais. Belo Horizonte, Organização Liv Sovik, editora UFMG, 2003.

HALL, S. A identidade cultural na pós-modernidade. Rio de Janeiro, trad. Tomaz Tadeu da Silva, Guaracira L. Louro, 11ª. ed. DP\&A, 2006.

MUNANGA, K. Educação e diversidade cultural. Cadernos Penesb - EdUFF. N ${ }^{\circ}$ 10, Niterói-RJ, jan-junho 2008-2010, pp. 77-85. Disponível em: http://www.uff.br/penesb/images/publicacoes/PENESB\%2010.pdf. Acesso em: 30 jul. de 2017.

MUNANGA, K. Negritude e identidade negra ou afrodescendente: um racismo ao avesso? Revista da Associação Brasileira de Pesquisadores/as 
Negros/as (ABPN), [S.I.], v. 4, n. 8, p. 06-14, out. 2012. Disponível em: https://abpnrevista.org.br/index.php/site/article/view/246. Acesso em: 19 de jul. 2019.

MUNANGA, K. Superando o Racismo na escola. Brasília, Ministério da Educação, SECAD, 2ed. revisada, 2005.

MUNANGA, K. Negritude usos e sentidos. Coleção cultura Negra e Identidade. Belo Horizonte, $3^{a}$ ed. Autêntica, 2009.

MUNANGA, K. Algumas considerações sobre a diversidade e a identidade negra no Brasil. In: BRASIL. Diversidade na educação: reflexões e experiências. Brasília: SEMTEC/MEC, 2003, pp. 36-49.

MUNANGA, K. Africanidades Brasileiras e Educação. Salto para o Futuro. Acervo, Tv escola- entrevista. 11/09/2008. Disponível em: https://api.tvescola.org.br/tve/salto-acervo/interview?idlnterview $=8449$. Acesso em: 30 jul. 2017.

POLLAK, M. Memória e identidade social. Conferência transcrita e traduzida por Monique Augras com edição de Dora Rocha. Rio de Janeiro, Estudos Históricos, vol. 5, n 10, 1992, pp. 200-212. Disponível em: http://bibliotecadigital.fgv.br/ojs/index.php/reh/article/view/1941/1080. Acesso em: 20 de ago. 2018.

SANTOS, M. de O. S; MACIEL, Francisca Izabel Pereira. A constituição da identidade negra nos textos e livros didáticos no ensino fundamental. Revista Exitus, Santarém, v. 10, p. 01-26 e020034, 2020. DOI: 10.24065/22379460.2020v10n0ID1258. Disponível em: http://www.ufopa.edu.br/portaldeperiodicos/index.php/revistaexitus/article/ view/1500. Acesso em: 18 mar. 2021.

SCHWARCZ, L. M. Nem preto nem branco, muito pelo contrário: cor e raça na sociabilidade brasileira. São Paulo: Ed. Claro Enigma, 2012.

VERGER, P. Orixás. Salvador, Editora Corrupio, 1981.

Recebido em: 28 de janeiro de 2021. Aprovado em: 04 de junho de 2021. Publicado em: 16 de junho de 2021. 